\title{
Analysis of Safety Culture Weaknesses in Chemical Safety Board Investigation Reports
}

\author{
Kenichi $\mathrm{UNO}^{1 *}$ \\ ${ }^{1}$ Japan Safety Competency Center, 4-14 Nihonbashi Yokoyama-cho, Chuo-ku, Tokyo 103-0003, Japan
}

\begin{abstract}
The U.S. Chemical Safety Board (CSB), an independent, non-regulatory federal agency that investigates the root causes of major chemical incidents, has firstly analyzed safety culture as an important element to maintain process safety in the investigation report of "BP America Refinery Explosion" in 2007. On the same year, the Center for Chemical Process Safety (CCPS) published Risk Based Process Safety (RBPS) in which process safety culture was newly added as an element. The author found six CSB reports which analyzed the weaknesses of safety culture and related them to the essential features of process safety culture in RBPS. Discussions are made on the results of the relations.
\end{abstract}

\section{Introduction}

The U.S. Chemical Safety Board (CSB), an independent, non-regulatory federal agency that investigates the root causes of major chemical incidents, has already issued more than one hundred investigation reports since 1998. It was in 2007 that CSB has firstly analyzed safety culture as an important element to maintain process safety in the investigation report of explosion and fire in BP Texas City refinery (The U.S. Chemical Safety Board, 2007). The author surveyed CSB reports after 2007 and found six reports which analyzed safety culture as one of the key issues. In these reports the results of the analysis were summarized into the weaknesses of safety culture and recommendations were made to improve them.

On the other hand, in the same year 2007, the Center for Chemical Process Safety (CCPS) published Risk Based Process Safety (RBPS) in which process safety culture was newly introduced as one of the twenty elements of process safety management systems (The Center for Chemical Process Safety, 2007). In RBPS, the key principles and the essential features of process safety culture are given and possible work activities with examples of ways to improve effectiveness are also given.

The author attempted to relate the weaknesses found in CSB reports to the weaknesses in the essential features of process safety culture in RBPS so that the ways to improve effectiveness can be utilized. In the next section, CSB reports containing analysis of safety culture are listed with brief summary of the accidents and the key principles and the essential features of process safety culture in RBPS are also introduced. The relations between the weaknesses will be discussed in section 3 .

\section{CSB Investigation Reports and RBPS Principles}

\subsection{CSB investigation reports with safety culture analysis}

Following six reports contain a chapter or a section analyzing safety culture. The title of each report is taken from the investigation name in CSB web site to facilitate easy access.

1) BP America Refinery Explosion (The U.S. Chemical Safety Board, 2007)

On March 23, 2005, explosions and fires occurred in BP Texas City refinery which resulted in 15 deaths and about 180 injuries. The refinery experienced two additional serious incidents just a few months after this disaster and CSB issued an urgent safety recommendation to convene an independent panel of experts to examine BP's corporate safety management systems and safety culture. The results of the panel were issued as "The Report of the BP U.S. Refineries Independent Safety Review Panel (Baker Panel Report)" (Baker et al., 2007) and were referred in the analysis of safety culture in this investigation report.

2) Tesoro Refinery Fatal Explosion and Fire (The U.S. Chemical Safety Board, 2014)

On April 2, 2010, a catastrophic rupture of a heat exchanger occurred in the Tesoro Anacortes refinery causing an explosion and an intense fire which fatally injured seven employees. The cause of the rupture was high temperature hydrogen attack.

*Corresponding author:ken1123@outlookl.com 
3) Chevron Refinery Fire (The U.S. Chemical Safety Board, 2015)

On August 6, 2012, a catastrophic pipe rupture occurred in the Chevron Richmond refinery causing a fire which resulted in a large plume of vapor, particles, and smoke travelling across the surrounding area. Six employees suffered minor injuries and approximately 15,000 people from surrounding communities sought medical treatment. The cause of the rupture was sulfidation corrosion.

4) Macondo Blowout and Explosion (The U.S. Chemical Safety Board, 2016a)

On April 20, 2010, the control of the Macondo oil well was lost during temporary well-abandonment activities on the Deepwater Horizon drilling rig resulting in an uncontrolled release of oil and gas from the well. On the rig, explosions and fire occurred which led to 11 deaths and 17 serious physical injuries and massive marine and coastal damage.

Post-Macondo safety culture assessment by BP did not assess whether the company's policies for risk management and operational success which were recommended in above mentioned Baker Panel Report were followed at Macondo and no new finding was added from the previous report.

5) Tesoro Martinez Sulfuric Acid Spill (The U.S. Chemical Safety Board, 2016b)

This report is the case study on process safety culture of the sulfuric acid releases occurring twice in succession at the Tesoro Martinez refinery. On February 12, 2014, the tubing of an acid sampling system came apart, spraying two operators and on March 10, 2014, two contract workers were sprayed during planned non-routine maintenance work. The investigation found that a weak process safety culture created conditions conducive to the recurrence of sulfuric acid incidents that caused worker injuries over several years.

6) Williams Olefin Plant Explosion and Fire (The U.S. Chemical Safety Board, 2016c)

On June 13, 2013, catastrophic equipment rupture, explosion, and fire occurred during non-routine operational activities in the Williams olefin plant, which killed two employees. The technical cause of the rupture was the introduction of the valves in 2001 which isolated the equipment from a protective pressure relief valve.

\subsection{Key Principles and Essential Features of Process Safety Culture in RBPS}

According to RBPS, following three key principles should be addressed in management systems for the process safety culture. Items listed for each key principle are the essential features. The abbreviation in the parenthesis at the end of each key principle and essential feature will be used in the following section 3 .

1) Maintain a dependable practice (DP)

a. Establish process safety as a core value (DP1) b. Provide strong leadership (DP2)

c. Establish and enforce high standards of performance (DP3)

d. Document the process safety culture emphasis and approach (DP4)

2) Develop and implement a sound culture (SC)

a. Maintain a sense of vulnerability (SC1)

b. Empower individuals to successfully fulfill their safety responsibilities $(\mathrm{SC} 2)$

c. Defer to expertise (SC3)

d. Ensure open and effective communications ( $\mathrm{SC} 4$ )

e. Establish a questioning/learning environment (SC5)

f. Foster mutual trust (SC6)

g. Provide timely response to process safety issues and concerns (SC7)

3) Monitor and Guide the Culture (MG)

a. Provide continuous monitoring of performance (MG1)

\section{CSB Safety Culture Weaknesses related to RBPS Essential Features}

In this section, the weaknesses of safety culture reported in the six investigation reports in section 2-1 are introduced and are related to either of the essential features listed in section 2-2. The abbreviation in the parenthesis at the end of each report and weakness will be used in Table 1 at the end of this section.

1) BP America Refinery Explosion (BP)

a. Lack of reporting and learning culture (BP1)

Reporting culture is directly related to communications (SC4) and communication is based on mutual trust (SC6) between employees and managers. Learning culture is directly related to questioning/learning environment (SC5).

b. Lack of focus on controlling major hazard risk (BP2)

BP executives relied only on personal safety metrics to drive safety performance, which means that they focused only on personal safety and not on process safety. This is related to the lack to establish process safety as a core value (DP1).

c. Safety implications of organizational change (BP3)

Poorly managed corporate mergers accompanied by leadership and organizational change and also the budget cuts both show weaknesses in safety culture. These factors are related to the lack in providing strong leadership (DP2) and the lack in establishing high standards of performance (DP3).

2) Tesoro Refinery Fatal Explosion and Fire (TA)

a. Management had normalized hazardous conditions (TA1)

The leaks from the heat exchanger which caused this accident had occurred repeatedly at every startup operation and hazardous conditions were routinely developed for years. This shows the weakness in 
establishing high standards of performance (DP3) where the normalization of deviance was accepted. Also, the weakness in providing timely response to process safety issues and concerns (SC7) is shown.

\section{b. Safety culture required proof of danger (TA2)}

In the process hazard analysis of this heat exchanger, experts used design parameters instead of actual operation conditions. This shows the weakness in maintaining the sense of vulnerability (SC1) in which the organization required employees to prove that the operation is high risk in order to prevent it rather than placing the burden of proof on determining that a condition is low risk.

3) Chevron Refinery Fire (Ch)

a. Decision to operate despite hazardous leaks (Ch1)

The similar decision was previously made two years ago and was repeated at the time of this accident. The acceptance of events that are not supposed to happen is related to the normalization of deviance included in establishing high standards of performance (DP3) and also related to provide timely response to process safety issues (SC7).

\section{b. Reluctance to use Stop Work Authority (Ch2)}

This reluctance was found from the safety culture questionnaire surveys performed at the refinery. By comparing the most recent results of the survey to those performed two years ago, it was concluded that the discrepancy may imply a perceived barrier in operators to using this authority. This reluctance can be related to the weakness in empowering individuals to successfully fulfil their responsibilities (SC2) and to that in providing timely response to process safety issues (SC7).

\section{c. Increased problems in equipment maintenance (Ch3)}

These problems were also found from the above mentioned culture survey comparison and can be related to the weakness in establishing high standards of performance (DP3) and to that in maintaining a sense of vulnerability (SC1).

\section{4) Macondo Blowout and Explosion (Ma)}

Post-Macondo safety culture assessment by BP did not assess the company's policies for risk management and operational success included in the Baker Panel Report mentioned in BP America Refinery Explosion. Thus, no new finding on the weakness is included in this investigation report.

\section{5) Tesoro Martinez Sulfuric Acid Spill (TM)}

a. Failure to learn from past incidents (TM1)

The history of similar incidents demonstrates failure to learn from the past incidents at the refinery through minimization of their seriousness. This failure is related to the weakness in establishing and enforcing high standards of performance (DP3) and to that in establishing a questioning/learning environment (SC5).

b. Weak management commitment to worker safety (TM2)
The tolerance of worker exposure to unsafe conditions and taking safer sampling equipment out of service show the weak management commitment to robust practices and procedures. This weakness is related to the weakness in providing strong leadership (DP2) and to that in providing timely response to process safety issues and concerns (SC7).

6) Williams Olefins Plant Explosion and Fire (Wi)

a. Deficiencies in the process safety management system (Wi1)

The deficiencies include a poorly conducted management of change and pre-startup safety review, ineffective safeguard selections and insufficient safeguard evaluation requirements, poor implementation of process hazard assessment action items, inadequate focus on developing and maintaining operating procedures, and allowing uncontrolled field equipment manipulations without first assessing hazards and developing a procedure. These deficiencies are related to the weaknesses in providing strong leadership (DP2) and to that in empowering individuals to successfully fulfill their safety responsibilities (SC2).

The results are listed in Table 1 using abbreviations. In this Table, the items in RBPS essential features which are not related to any weakness in the reports are omitted.

Table 1. Weaknesses related to essential features

\begin{tabular}{|c|c|c|c|c|c|c|c|c|c|c|}
\hline & & \multicolumn{3}{|c|}{$\begin{array}{c}\text { Dependable } \\
\text { Practice }\end{array}$} & \multicolumn{6}{|c|}{ Sound Culture } \\
\hline & & 1 & 2 & 3 & 1 & 2 & 4 & 5 & 6 & 7 \\
\hline \multirow[t]{3}{*}{ BP } & 1 & & & & & & 0 & 0 & 0 & \\
\hline & 2 & 0 & & & & & & & & \\
\hline & 3 & & 0 & 0 & & & & & & \\
\hline \multirow[t]{2}{*}{ TA } & 1 & & & $\mathrm{O}$ & & & & & & 0 \\
\hline & 2 & & & & 0 & & & & & \\
\hline \multirow[t]{3}{*}{$\overline{\mathrm{Ch}}$} & 1 & & & 0 & 0 & & & & & \\
\hline & 2 & & & & & 0 & & & & 0 \\
\hline & 3 & & & 0 & 0 & & & & & \\
\hline $\mathrm{Ma}$ & - & - & - & - & - & - & - & - & & - \\
\hline \multirow[t]{2}{*}{ TM } & 1 & & & 0 & & & & 0 & & \\
\hline & 2 & & 0 & & & & & & & 0 \\
\hline$\overline{W i}$ & 1 & & 0 & & & 0 & & & & \\
\hline
\end{tabular}

\section{Discussions}

The weaknesses in safety culture found in five reports excluding Macondo were related to the weaknesses in the essential features of process safety culture in RBPS. These relations give some insights to the investigation results and also to the essential features of RBPS.

Firstly, the depth of investigation of safety culture in each report varies considerably. As mentioned before, safety culture findings in BP report are based on Baker Panel Report, which analyzed not only Texas City 
refinery but all five refineries owned by BP US. Thus the investigation included all layers involved in safety culture including top management. This seems to be the reason why weakness in establishing process safety as a core value (DP1) is pointed out in BP, which is very important as culture is said to start from the top management. In fact there was no new finding in Macondo because the same company was already investigated five years earlier.

On the contrary, in Williams report, the weaknesses found are only in the implementation of the process safety management systems, which are mainly related to managers and individuals and the involvement of top management is not analyzed. Considering the importance of top management in safety culture, further investigation on the background of the poor implementation seems to be necessary.

Secondly, "Establish and enforce high standards of performance (DP3)" was related to weaknesses in four reports (BP, TA, Ch, TM) and was most frequently related feature. The accidents investigated in these four reports were preceded by repeated occurrence of similar incidents. Lack or delay of sufficient measures to avoid reoccurrence of similar incidents is due to the weakness in this feature, which is also expressed as the normalization of deviance, a typical feature of weak safety culture.

Also, "Provide timely response to process safety issues and concerns (SC7)" was related to weaknesses in three reports (TA, Ch, TM). As a brief period is allowed between recognition of a problem and suffering the consequences of the problem, weaknesses in timely and quick response in all layers of management lead to worst results. This feature seems to be closely related to above mentioned DP3.

Lastly, not all essential features of process safety culture in RBPS are mutually exclusive and some seems to have causal relationships. "Establish and enforce high standard (DP3)" tells you never to accept normalization of deviance, which can be prevented by resolving mismatches between practices and standards in timely manner discussed in "Providing timely response to process safety issues and concerns (SC7)". The normalization of deviance is also related to "Maintain a sense of vulnerability (SC1)" which suggests to avoid complacency, the origin of normalization of deviance.

Also, "Foster mutual trust (SC6)" can be seen as a basis and a result for "Ensuring open and effective communications (SC4)" and "Establishing a questioning/learning environment (SC5)" .

These discussions seems to suggest that you should not be so strict in relating weaknesses of safety culture to certain essential features of RBPS but use the relations found to widen the view in consideration of measures to reinforce safety culture.

\section{Conclusion}

By surveying CSB investigation reports after BP in 2007, the author found six reports including analysis of safety culture. The weaknesses of safety culture pointed out in these reports were related to the weaknesses in essential features of process safety culture in RBPS. The results give insights on the depth of each investigation, the most frequently related essential feature, and the relationships among essential features themselves.

Though the reports including analysis of safety culture are still limited, approaches to analyze safety culture are being accumulated.

\section{References}

Baker, J. A. III, F. L. Bowman, G. Erwin, S. Gorton, D. Hendershot, N. Leveson, S. Priest, I. Rosenthal, P. V. Tebo, D. A. Wiegmann, and L. D. Wilson; "The Report of the BP U.S. Refineries Independent Safety Review Panel,"

https://www.csb.gov/assets/1/20/baker_panel_report1.pd f?13842 (2007)

The Center for Chemical Process Safety; Guidelines for Risk Based Process Safety, pp. 42-67, John Wiley \& Sons, Inc., New Jersey, U.S.A. (2007)

The U.S. Chemical Safety Board; Investigation Report Refinery Explosion and Fire, https://www.csb.gov/bpamerica-refinery-explosion/ (2007)

The U.S. Chemical Safety Board; Investigation Report Catastrophic Rupture of Heat Exchanger, https://www.csb.gov/tesoro-refinery-fatal-explosion-andfire/ (2014)

The Chemical Safety Board; Investigation Report Chevron Richmond Refinery Pipe Rupture and Fire, https://www.csb.gov/chevron-refinery-fire/ , (2015)

The U.S. Chemical Safety Board; Investigation Report Executive Summary Drilling Rig Explosion and Fire at the Macondo Well, https://www.csb.gov/macondoblowout-and-explosion/ (2016a)

The U.S. Chemical Safety Board; Case Study Tesoro Martinez Refinery, https://www.csb.gov/tesoromartinez-sulfuric-acid-spill/ (2016b)

The U.S. Chemical Safety Board; Case Study Williams Geismer Olefin Plant, https://www.csb.gov/williamsolefins-plant-explosion-and-fire-/ (2016c) 